\title{
Do age and professional rank influence the order of authorship in scientific publications? Some evidence from a micro-level perspective
}

\author{
Rodrigo Costas $\cdot$ María Bordons
}

Received: 26 October 2010/Published online: 20 March 2011

(C) The Author(s) 2011. This article is published with open access at Springerlink.com

\begin{abstract}
Scientific authorship has important implications in science since it reflects the contribution to research of the different individual scientists and it is considered by evaluation committees in research assessment processes. This study analyses the order of authorship in the scientific output of 1,064 permanent scientists at the Spanish CSIC (WoS, 1994-2004). The influence of age, professional rank and bibliometric profile of scientists over the position of their names in the byline of publications is explored in three different research areas: Biology and Biomedicine, Materials Science and Natural Resources. There is a strong trend for signatures of younger researchers and those in the lower professional ranks to appear in the first position (junior signing pattern), while more veteran or highlyranked ones, who tend to play supervisory functions in research, are proportionally more likely to sign in the last position (senior signing pattern). Professional rank and age have an effect on authorship order in the three fields analysed, but there are inter-field differences. Authorship patterns are especially marked in the most collaboration-intensive field (i.e. Biology and Biomedicine), where professional rank seems to be more significant than age in determining the role of scientists in research as seen through their authorship patterns, while age has a more significant effect in the least collaboration-intensive field (Natural Resources).
\end{abstract}

Keywords Order of authorship - Micro-level analysis · CSIC · Individual level analysis · Bibliometrics · Authorship · Age analysis

\footnotetext{
R. Costas $(\bowtie)$

Centre for Science and Technology Studies (CWTS), Leiden University, P.O. Box 905, 2300AX Leiden, The Netherlands e-mail: rcostas@cwts.leidenuniv.nl
}

M. Bordons

Instituto de Estudios Documentales sobre Ciencia y Tecnología (IEDCYT),

Center of Human and Social Sciences (CCHS), CSIC, Albasanz, 26-28, 28037 Madrid, Spain 


\section{Introduction}

Bibliometric indicators at the micro level constitute a valuable tool not only for supporting research assessment of scientists but also for the better understanding of the scientific process. Studies dealing with this second purpose are less common in the literature but equally attractive, since they enable us to delve into different aspects of the behaviour of researchers such as their collaboration habits and interactions, their different roles in the production of new knowledge or the determinants of their scientific performance. Interesting examples of this use of bibliometric indicators are the so-called "bibliometric portraits", which pursue the bibliometric characterisation of individual scientists (Kalyane and Munnolli 1995; Prakasan et al. 2009), reflecting their personal history (Cronin and Shaw 2002). Moreover, studies developed to explore inter-gender differences in the behaviour of scientists (Fox 2005; Mauleon and Bordons 2006) or those focused on the analysis of main determinants of successful professional careers (Carayol and Matt 2004) also deserve being mentioned. The combination of bibliometric indicators with other methodologies such as surveys or questionnaires have emerged as very relevant, since it enables the introduction of a more sociological perspective in the study of research performance (Feist 1993; Hemlin and Gustafsson 1996; Prpic 2000; Fox and Stephan 2001).

This paper focuses on one specific aspect of the publication of research results: authorship and authors' name order in publications. Multi-authored documents are now the norm in science as a result of the important role of collaboration in research (Bordons and Gómez 2000; Hara et al. 2003). Due to the increasing complexity of research, teamwork and inter-scientist collaboration have become essential for the advancement of science. Scientists with different skills and specialisation profiles may successfully collaborate for the development of research projects and the creation of new knowledge.

The main role of authorship is giving credit for the scientific contribution of authors, but also assigning responsibility for their published research (Biagioli 1998; Pontille 2004). There are different guidelines concerning authorship criteria and although none of them is universally respected, it is usually accepted that authorship criteria include (a) involvement in conception, planning and execution of the research work, (b) interpretation of results, (c) writing a substantial portion of the manuscript, and (d) final approval of the version to be published (ICMJE 2010; Cronenwett and Seeger 2005). However, all authors do not contribute equally to the research published in a paper. Interestingly, in some disciplines the sequence of authors in the byline of publications provides significant information about the contribution of authors to the research or, at least, enables us to identify principal authors which occupy the "key positions" in the paper. This is currently true, although the upward trend observed in the number of authors per paper makes it increasingly difficult to assess the nature and extent of the contribution of each author (Birnholtz 2006), as well as to discern who is accountable for the integrity of the work (Bellis 2009).

In spite of the abovementioned limitations, authorship in peer-reviewed journals is basic for academic appointments and is used in research evaluation processes associated to getting promotion, tenure, prizes, funding and, in the long term, professional prestige (Tscharntke et al. 2007). Moreover, the order of authorship is sometimes taken into account in bibliometric studies, since credit among co-authors can be distributed in such a way that the greater percentage share of the credit is given to those who contributed the most (see for example $\mathrm{Hu} 2009$ or $\mathrm{Hu}$ et al. 2010, Vinkler 2010). Accordingly, the knowledge of the implicit existing conventions concerning the order of authorship within each field is very useful for evaluators-also for readers and editors - who want to assign the correct credit and accountability to authors. 
Concerning the meaning of the order of authors' names in the byline of publications important differences by fields have been described (Pontille 2004). Some scientific associations have a formal policy on author order (Osborne and Holland 2009), but this is not the norm and different practices exist depending on the disciplines and even by research group and country, since the practice of signing also may reflect national traditions in less international disciplines (Pontille 2004). Moreover, slight differences depending on the basic/clinical nature of research, measured through the scope of journals or the specialisation background of scientists, have been described in some specific biomedical disciplines (Savitz 1999).

The most widely accepted convention among the experimental sciences is that the most important positions are the first and the last (Zuckerman 1968). In this sense, first-position authors are very often responsible for the experimental work supervised by the last-position author (Moed 2000), who has a role of supervision and leadership of the research (Beveridge and Morris 2007; Shapiro et al. 1994). The importance of the first-position author's contribution to the papers is supported by the fact that he/she is very often the reprint author (Costas and Iribarren-Maestro 2007; Mattsson et al. 2010). The remaining authors tend to appear in intermediate positions in descending order of their contribution, with senior authors normally listed at the end. However, in some disciplines such as Mathematics, Economics or High Energy Physics, alphabetical order of authors is followed (AMS 2004; Mauleon and Bordons 2007; Engers et al. 1999; Birnholtz 2006; Frandsen and Nicolaisen 2010).

Browsing through the literature, the order of authors in the byline has been studied from different points of view. Inter-field differences in the interpretation of author order in papers have been put forward in a number of studies, in which the prevailing policy was described (for example Mendki 2006), sometimes contrasted with case studies that report authors' views on their contribution to papers (Shapiro et al. 1994), or with the perceptions on author contributions by scientific committees based on author's position (Wren and Kozak 2007). The influence of different variables, such as professional rank and age, on authorship practices has also been explored in the literature, noting that scientists tend to sign more as last author and less often as first author as they get older (Gingras et al. 2008) and as they go up in the hierarchy (Drenth 1998).

This paper focuses on the relationship between the position of authors in the byline and three variables: age, professional rank and research performance of scientists. Although some of these aspects have been previously analysed, our purpose here is to study the interaction between them which is an original approach. If principal researchers tend to sign as last authors, we would also expect research professors to be found more frequently in such a position. However, age must also be an influential factor, since those with a long professional career are more likely to have attained a leadership position in a consolidated team. In addition, the authorship pattern of "top scientists"-identified following the methodology suggested by Costas et al. (2010) for the use of bibliometric indicators at the individual level - is explored. Finally, the interaction between these variables is examined.

\section{Objectives}

The main objective of this article is to study authorship practices in publications as regards the order of names in the byline. The influence of the age, professional rank and bibliometric profile of scientists over the author's position in the byline of publications is explored-as well as the interaction between these variables-in three different research areas. 
The following questions are addressed: Are there specific authorship patterns for junior and senior scientists at the Spanish National Research Council (Consejo Superior de Investigaciones Cientificas, CSIC)? What is the influential role of professional rank, age and scientific performance class (and their interaction) on authorship patterns? Are there any differences by field in the effect of these criteria? Can we explore the position of scientists in the social structure of Science through their signing habits?

\section{Methodology}

This study is based on the bibliometric analysis of 1,064 permanent researchers working at the Spanish CSIC in 2004 with a full time position. For research management purposes, scientists at the CSIC are organised in seven research areas ${ }^{1}$ according to their scientific topics, three of which are subject to analysis in this study: Biology and Biomedicine (388 scientists), Natural Resources (348) and Materials Science (327). These researchers are also organised in three professional ranks: Tenured Scientist (the lowest rank-558 researchers), Research Scientist (the intermediate rank-269) and Research Professor (the highest rank-237). The full name, age, professional rank and research institute of each scientist were provided for each of the three areas under study.

The scientific production of the scientists under survey published in journals covered by the Web of Science (WoS) during the period 1994-2004 was downloaded and assigned to their authors. Several methodologies for the correct matching of authors and documents were applied (see Costas and Bordons 2006). Documents published by scientists during their stays abroad were also included in the study, and all document types were considered.

For every scientist, his/her number of documents in the period under analysis was recorded as well as his/her position in the byline of the documents. The following indicators were obtained:

a. \% Documents in First position: percentage of a scientist's publications in which he/she appears as first author.

b. \% Documents in Last position: percentage of publications that each scientist has published as last author.

c. \% Documents in Middle position: percentage of publications where the scientist appears in any intermediate position.

d. \% Single-authored documents: percentage of publications where the scientist appears alone (not shown in this paper, but mentioned here because the sum of the four described indicators for a given scientist accounts for $100 \%$ of his/her production).

These indicators were analysed in relation to the professional rank, age and scientific class of scientists. The three professional ranks existing at the CSIC for permanent scientists were considered: tenured scientist, research scientist and research professor. The age of scientists was considered as a quantitative variable but also a categorical one, including three age-groups: $\leq 44$ years (young), 45-54 years (middle-aged) and $\geq 55$ years (veteran). ${ }^{2}$

\footnotetext{
${ }^{1}$ Agricultural Sciences, Biology and Biomedicine, Chemical Sciences and Technology, Food Science and Technology, Humanities and Social Sciences, Materials Sciences and Technology, Natural Resources, Physical Sciences and Technology.

${ }^{2}$ Age-group limits determined by the percentile values in the distribution of scientists by age (P25 $=44$ years old and $\mathrm{P} 75=55$ years old).
} 
In this paper, we also use the concept of "scientific performance class" which refers to a three-group classification of scientists according to their performance in three bibliometric dimensions (Production, Observed Impact and Expected Impact). These three scientific performance classes are: top, medium and low. Top researchers are the ones with a high performance in at least two of the three dimensions, medium class scientists present an intermediate performance in two of the three dimensions and low class researchers have a low performance in at least two of the three dimensions suggested (cf. Costas et al. 2010).

The statistical analysis of data was carried out with SPSS. Tests for non-parametric variables were applied for the comparison between means (U Mann-Whitney test and Kruskal-Wallis test). The generalised linear model was used to study the influence of age and professional rank on the author's position in the byline of publications as well as to explore the interaction between both factors.

\section{Results}

First of all, some general data about the production of the researchers under analysis are shown. The researchers of the three areas account for a total of 24,982 documents: 9,660 in Materials Science, 9,318 in Biology and Biomedicine and 6,102 in Natural Resources; receiving 80,546, 189,699 and 56,940 citations, respectively. For additional data on the research performance of scientists in these areas we refer to Costas et al. (2010).

Only 26 scientists $(2.4 \%)$ had no WoS publications during the period of analysis. This paper focuses on the research performance of the remaining 1,038 scientists, which have at least 1 publication during the reference period. Altogether, the distribution of these scientists by professional rank was as follows: $52 \%$ were tenured scientists, $25 \%$ were research scientists and $22 \%$ were research professors. In respect to age, we can mention that around $31 \%$ of scientists were labelled as "young" (less than 45 years), $39 \%$ were "middle-aged" (45-54 years old) and 30\% were in the "veteran" group ( $\geq 55$ years old) (Table 1).

The relationship between the professional rank and age of scientists is displayed in Table 2. We can observe that young scientists predominate in the lowest rank, while middle-aged ones are almost half of the research scientists and scientists over 55 constitute

Table 1 Distribution of scientists by age, professional rank and scientific area

\begin{tabular}{llllr}
\hline & $\begin{array}{l}\text { Biology and Biomedicine } \\
(\%)\end{array}$ & $\begin{array}{l}\text { Materials Science } \\
(\%)\end{array}$ & $\begin{array}{l}\text { Natural Resources } \\
(\%)\end{array}$ & Total $(\%)$ \\
\hline Age & & & & \\
$\quad \leq 44$ years & $112(28.9)$ & $105(32.1)$ & $115(33.0)$ & $332(31.2)$ \\
$45-54$ years & $173(44.6)$ & $113(34.6)$ & $132(37.8)$ & $418(39.3)$ \\
$\geq 55$ years & $103(26.5)$ & $109(33.3)$ & $102(29.2)$ & $314(29.5)$ \\
$\quad$ Total & $388(100)$ & $327(100)$ & $349(100)$ & $1,064(100)$ \\
$\begin{array}{l}\text { Professional rank } \\
\text { Tenured }\end{array}$ & $188(48.4)$ & $164(50.1)$ & $206(59.0)$ & $558(52.4)$ \\
$\begin{array}{l}\text { Scientist } \\
\text { Research }\end{array}$ & $105(27.1)$ & $80(24.5)$ & $84(24.1)$ & $269(25.3)$ \\
$\begin{array}{l}\text { Scientist } \\
\text { Research }\end{array}$ & $95(24.5)$ & $83(25.4)$ & $59(16.9)$ & $237(22.3)$ \\
$\begin{array}{l}\text { Professor } \\
\text { Total }\end{array}$ & $388(100)$ & $327(100)$ & $349(100)$ & $1,064(100)$ \\
\hline
\end{tabular}


Table 2 Distribution of scientists by professional rank and age (all areas combined)

\begin{tabular}{llcrr}
\hline & \multicolumn{2}{l}{ Professional rank } & & Total (\%) \\
\cline { 2 - 4 } & Tenured scientist $(\%)$ & Scientific researcher $(\%)$ & Research professor $(\%)$ & \\
\hline$\leq 44$ years & $273(48.9)$ & $49(18.2)$ & $10(4.2)$ & $332(31.2)$ \\
$45-54$ years & $194(34.8)$ & $126(46.8)$ & $98(41.4)$ & $418(39.3)$ \\
$\geq 55$ years & $91(16.3)$ & $94(34.9)$ & $129(54.4)$ & $314(29.5)$ \\
Total & $558(100)$ & $269(100)$ & $237(100)$ & $1,064(100)$ \\
\hline
\end{tabular}

Note: data disaggregated by areas in the Appendix

Table 3 Average number of authors and centres per document by area

\begin{tabular}{lll}
\hline & No. Authors/doc. & No.Centres/doc. \\
\hline Biology and Biomedicine $(n=9,318)$ & $6.69(22.53)$ & $2.59(4.64)$ \\
Materials Science $(n=9,660)$ & $4.85(2.20)$ & $2.30(1.24)$ \\
Natural Resources $(n=6,102)$ & $3.98(2.77)$ & $2.22(1.55)$ \\
\hline
\end{tabular}

Data expressed as average (standard deviation)

more than half of the research professors. Although there are small inter-field differences (see Appendix), this general pattern was found in the three scientific areas.

The average number of authors per document can be considered as a proxy for the average size of teams in each area (Table 3). It is interesting to observe that the smallest team size corresponds to Natural Resources (around four authors) and the largest to Biology and Biomedicine (around seven authors). As the number of authors per document increases, the contribution of the different authors is more diffuse and the ambiguity of authorship increases. However, the first and last positions maintain in many disciplines a special meaning as far as their contribution to the research is concerned.

In the following sections the trend of authors to sign as first and last authors of publications is analysed in relation to their professional rank, age and scientific performance class.

\section{Professional rank}

The author's position in the byline of publications regarding their professional rank is analysed in each of the three areas under study in Fig. 1.

Figure 1 presents the distribution of the percentage of documents signed by researchers as first and last author in each of the three professional ranks. The thick line within the box plots represents the median of the distribution; the lower and upper hinges of the boxes represent the lower and upper quartiles of the distribution (meaning that $50 \%$ of all the researchers are included in the box). Finally, the circles and asterisks in the upper part of the figures represent the outliers and extreme values of the different distributions. ${ }^{3}$

These figures show a clear pattern for the three scientific areas. As we go up in the professional rank, the percentage of first-authored papers decreases and the percentage of

\footnotetext{
3 SPSS considers extreme values (asterisks) those which are more than three box-lengths from either end of the box, while the term outliers (circles) is used to described those values which are between one and a half and three box-lengths from either end of the box.
} 

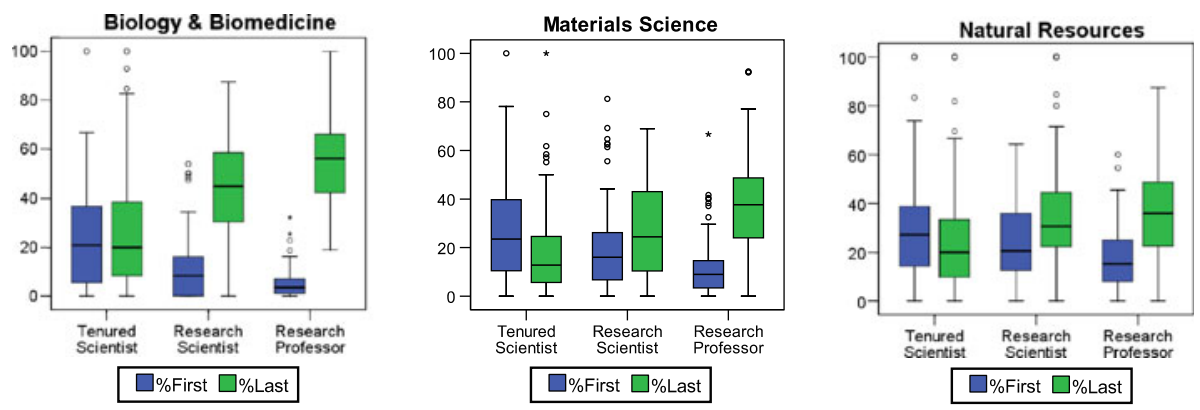

Fig. 1 Share of first and last-authored documents by professional rank and area

last-authored papers rises. Differences among professional ranks in the percentage of firstauthored documents are found, as well as in the percentage of last-authored papers $(P<0.001$ in both cases, Kruskal-Wallis test), which means that the position of authors in the byline is related to their professional rank. Within each rank, differences between the percentage of first and last-authored documents are generally observed. Tenured scientists publish proportionally more documents in the first position and fewer in the last position, while research scientists and research professors publish proportionally more in last position and less in the initial position $(P<0.01$, signed test). The only exception concerns tenured scientists in Biology and Biomedicine, who sign indistinctly in the first or last position (no significant differences were found).

Signing patterns are especially marked in Biology and Biomedicine where research professors show the lowest percentage of first-authored documents (below 10\%) and the highest percentage of last-authored documents (around 50\%). On the other end of spectrum, we find Natural Resources, with smoother signing patterns (research professors sign around $20 \%$ of their documents as first author and $40 \%$ as last author). An intermediate situation is revealed for the area of Materials Science.

Age

The distribution of the percentage of documents signed by scientists in the first and the last positions according to their age is shown for the three areas under study in Fig. 2.

A very clear pattern is observed in all three areas: the percentage of first-authored documents decreases with age, while the percentage of last-authored documents increases.
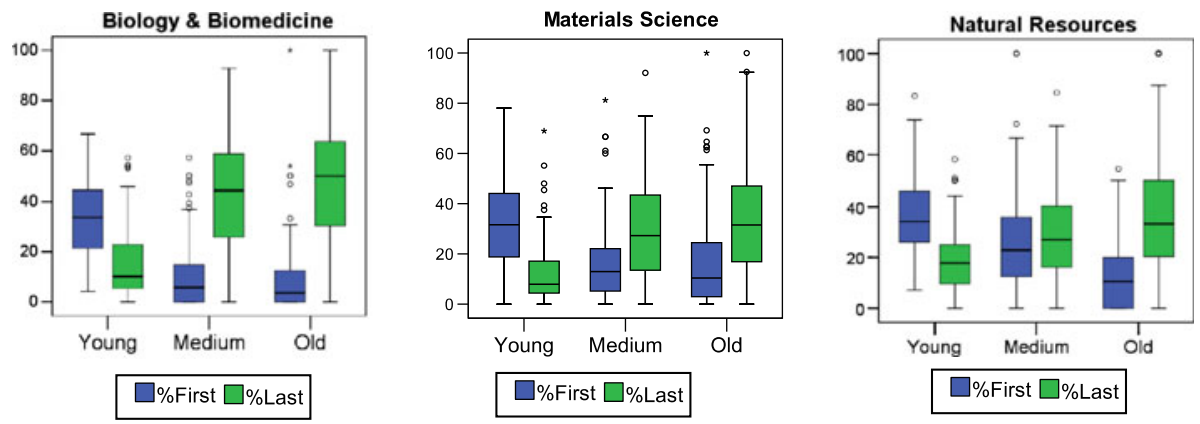

Fig. 2 Share of first and last-authored documents by age-group and area 
Younger researchers present the highest percentage of documents signed in first position and the lowest percentage in last position; while the contrary holds for older researchers who present the highest percentages of documents signed in last position and the lowest percentage in first position. Statistical significant differences were found between young researchers and the other two groups of scientists $(P<0.000)$. These results show that author position in the byline of publications in these research areas is clearly age-related, which is consistent with earlier results (e.g. Gingras et al. 2008).

\section{Scientific performance class}

Differences in the author's byline position according to the scientific performance class of researchers are explored in Fig. 3. In this case, contrary to our previous analysis, no clear and common pattern for the three areas is observed.

In Natural Resources and Materials Science the three classes of scientists present similar percentages of documents signed in first and last position; in fact, there are no inter-class differences in signing habits.

In the case of Biology and Biomedicine, the percentage of first-authored documents decreases from top to low class scientists, while the opposite trend is observed for the percentage of last-authored papers. However, the influential factor here is not scientific class, but age, which increases from top to low class (see previous section). Within each scientific class, large differences in first/last-authorship by age were found. This picture is only observed in Biology and Biomedicine due to the sharper age-related signing patterns described for this field.

Evolution of author's position in the byline of publications according to age

This analysis is based on the age of scientists when publishing the documents. Therefore, the age of researchers in the year of publication ("age of publication") as well as their position in the byline are taken into account for each document. Documents with several researchers with different ages are counted for each age, considering that duplications are suitable for the better understanding of authorship practices of researchers according to their age.

Figure 4 shows the evolution of the percentage of documents signed by scientists in first, middle and last positions for each area depending on their age. In the field of Natural Resources, a total of 6,031 documents were published by researchers aged between 26 and 60. As we can see, scientists under 34 tend to sign mainly in first position. As the age of
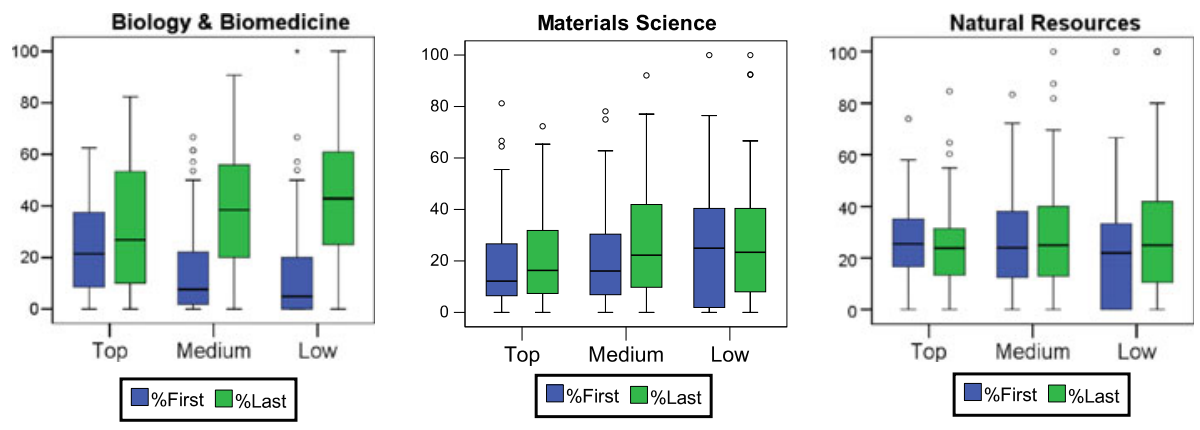

Fig. 3 Share of first and last-authored documents by scientific class and area 
researchers increases, they tend to change their position in the byline of papers from the first to the last one. In Natural Resources, the "shift age", when researchers start to sign more in last than in first position, is around 38-39, although quite similar percentages of documents are signed in both positions for scientists in the 38-46 age-group. Over the age of 46, scientists tend to sign mainly as last or middle author, and they seldom appear as first author.

In the case of Biology and Biomedicine, a total of 8,922 documents have been published by researchers aged between 26 and 60 . The pattern revealed here is very similar to that described for Natural Resources: first-authored documents predominate among the youngest scientists while this author's byline position is infrequent for veteran scientists, who

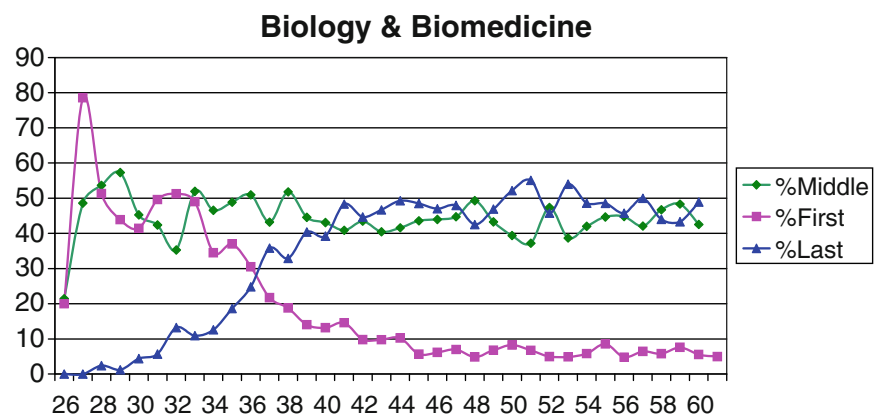

Age of researchers at the moment of publication (age range:26-60)
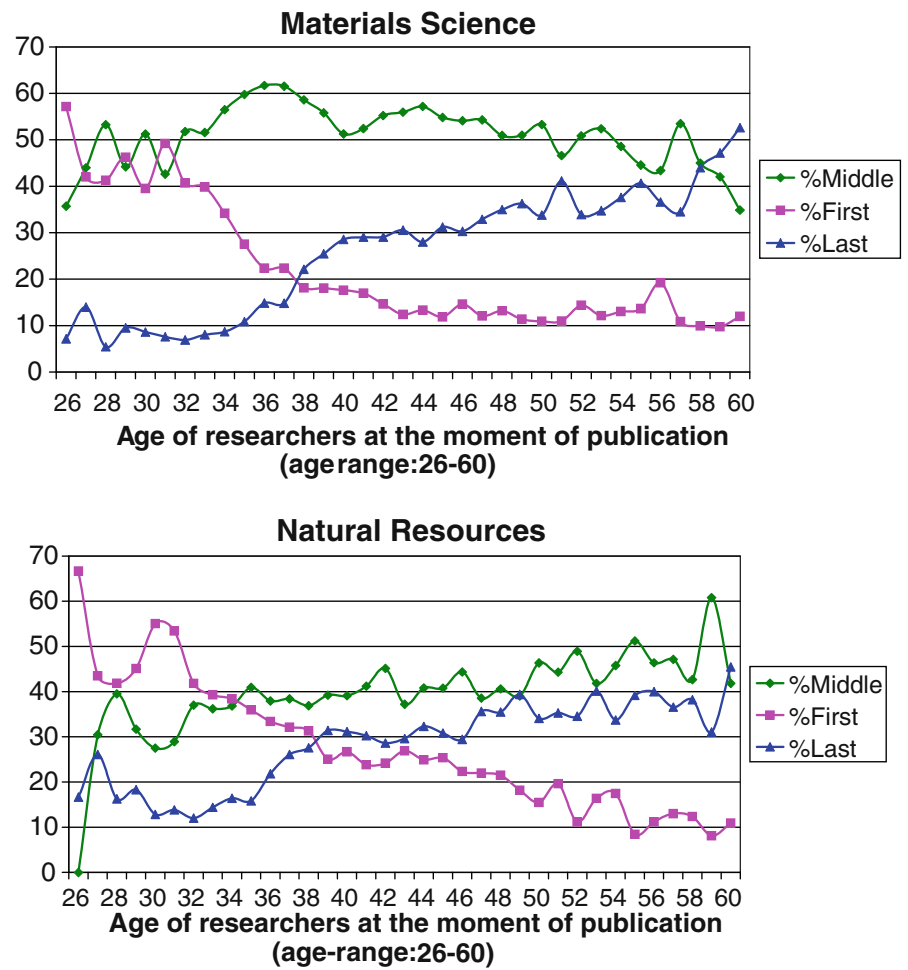

Fig. 4 Evolution of author's position in the byline of publications by age 
tend to sign in the middle or last position. In this area, the shift age is 35-36 (slightly earlier than for Natural Resources). The intermediate author's byline position is very frequent along the whole life of researchers (it appears in around 40-50\% of their production), partly due to the higher number of co-authors in this particular area.

In Materials Science, a total of 9,537 documents published by scientists aged between 26 and 60 are analysed. The same tendency revealed for the other two areas is observed. In this case the shift-age corresponds to scientists aged 37-38. Besides, documents signed in intermediate positions are more usual than in the other two areas during practically the whole life of researchers.

In Natural Resources, scientists keep signing as first-author of documents for a longer period when compared to the other two areas: scientists aged 47 appear as first authors in around $20 \%$ of the documents in this area vs. $10 \%$ in Materials Science and Biology and Biomedicine.

Signing patterns are especially evident in Biology and Biomedicine where scientists tend to acquire a supervisory role (last position) earlier and in a more sustained manner than in the other areas.

Interaction between professional rank and age

We have seen that both age and professional rank are influential factors on the position of authors in the byline, but which one carries more weight? It is clear that as age and rank rise, the probability of signing in the last position also does. But what happens with those scientists that never attain the highest rank and get older in the lowest rank? What about those brilliant scientists that attain the highest rank in their youth? Do their signing habits resemble those of their age-group colleagues or those that are standard for their professional rank? To explore these issues (that have not been previously dealt with in the literature) the effects of age and professional rank on the signing habits of scientists were analysed from a global perspective. A multivariable generalised linear model was used, since it provides variance analysis for multiple dependent variables (percentage of firstauthored documents and percentage of last-authored documents) which follow a probability distribution other than the normal distribution (Poisson distribution). It allows us to assess the effects of the relevant factors (age and professional rank) on the dependent variables as well as the interaction between factors.

Our analysis shows that the percentage of last-authored documents is influenced by the professional rank and age of scientists in Biology and Biomedicine and Natural Resources. In these areas, there is no interaction between age and rank (Table 4), that is, for all professional ranks the percentage of last-authored documents tends to increase with age (Fig. 5). Interestingly, the effect of the professional rank is higher than that of age in Biology and Biomedicine (higher Wald Chi square value ${ }^{4}$ ), while both variables show a very similar effect in the field of Natural Resources. In Materials Science, the professional rank is the major influential variable. An interaction between age and rank is identified in this area due to the fact that the percentage of last-authored documents tends to increase with age for tenured scientists and research professors, but this pattern is not so apparent for research scientists (Fig. 5).

Professional rank and age are also influential factors on the percentage of first-authored documents. The percentage of first-authored documents tends to decrease as scientists get older (Fig. 5). We can see that rank is the major influential factor in both Biology and

${ }^{4}$ The Wald test is a parametric test that can be used to test the statistical significance of the different coefficients in a model. 
Table 4 Significance of the effects of factors on the model obtained (generalised linear model)

\begin{tabular}{|c|c|c|c|c|c|c|}
\hline \multirow[t]{3}{*}{ Scientific area } & \multicolumn{3}{|l|}{$\%$ Last author } & \multicolumn{3}{|l|}{$\%$ First author } \\
\hline & \multicolumn{3}{|l|}{ Type III } & \multicolumn{3}{|l|}{ Type III } \\
\hline & Wald Chi-square & df & Sig. & Wald Chi-square & df & Sig. \\
\hline \multicolumn{7}{|l|}{ Biology and biomedicine } \\
\hline (Intercept) & $7,767.98$ & 1 & 0.000 & 584.24 & 1 & 0.000 \\
\hline Professional rank & 52.87 & 2 & 0.000 & 32.10 & 2 & 0.000 \\
\hline Age & 16.85 & 2 & 0.000 & 2.40 & 2 & NS \\
\hline Professional rank * Age & 10.89 & 4 & NS & 7.71 & 4 & NS \\
\hline \multicolumn{7}{|l|}{ Materials science } \\
\hline (Intercept) & $3,350.61$ & 1 & 0.000 & $1,645.69$ & 1 & 0.000 \\
\hline Professional rank & 16.74 & 2 & 0.000 & 6.11 & 2 & 0.047 \\
\hline Age & 4.04 & 2 & NS & 3.21 & 2 & NS \\
\hline Professional rank $*$ Age & 19.98 & 4 & 0.001 & 18.84 & 4 & 0.001 \\
\hline \multicolumn{7}{|l|}{ Natural resources } \\
\hline (Intercept) & $4,620.75$ & 1 & 0.000 & $3,164.01$ & 1 & 0.000 \\
\hline Professional rank & 9.42 & 2 & 0.009 & 1.85 & 2 & NS \\
\hline Age & 10.86 & 2 & 0.004 & 36.00 & 2 & 0.000 \\
\hline Professional rank $*$ Age & 2.50 & 4 & NS & 3.25 & 4 & NS \\
\hline
\end{tabular}

Method generalised linear model, parameter estimation by Fisher method, Pearson square scale, SPSS 17

Biomedicine and Materials Science, corrected by age in the latter case (there is an interaction between professional rank and age), while age is the major influential factor in Natural Resources (Table 4).

\section{Discussion and conclusions}

First of all, we would like to mention some limitations to the present study. This is mainly a cross-sectional study (with the exception of the analysis in Fig. 4), so each scientist was considered in his/her professional rank in 2004, although some of them could have been promoted during the period under analysis. Although this issue should be taken into account, we consider that it does not impair the validity of our study since (a) scientists promoted constitute a small percentage of the total, and (b) scientists display rather stable authorship patterns that are not immediately affected by a promotion.

Junior and senior signing patterns

Our results show that authorship patterns observed in the three areas analysed are clearly influenced by the age and professional rank of scientists, although there exist some differences by area. In general, there is a strong trend for signatures of younger researchers and those in the lower professional ranks to appear in the first position, while more veteran or highly-ranked ones are proportionally more likely to sign in the last position. Accordingly, a junior signing pattern can be described in all three areas, characterised by the predominance of first-authored versus last-authored documents, as well as a senior signing pattern, where last-authored documents largely exceed first-authored ones. 

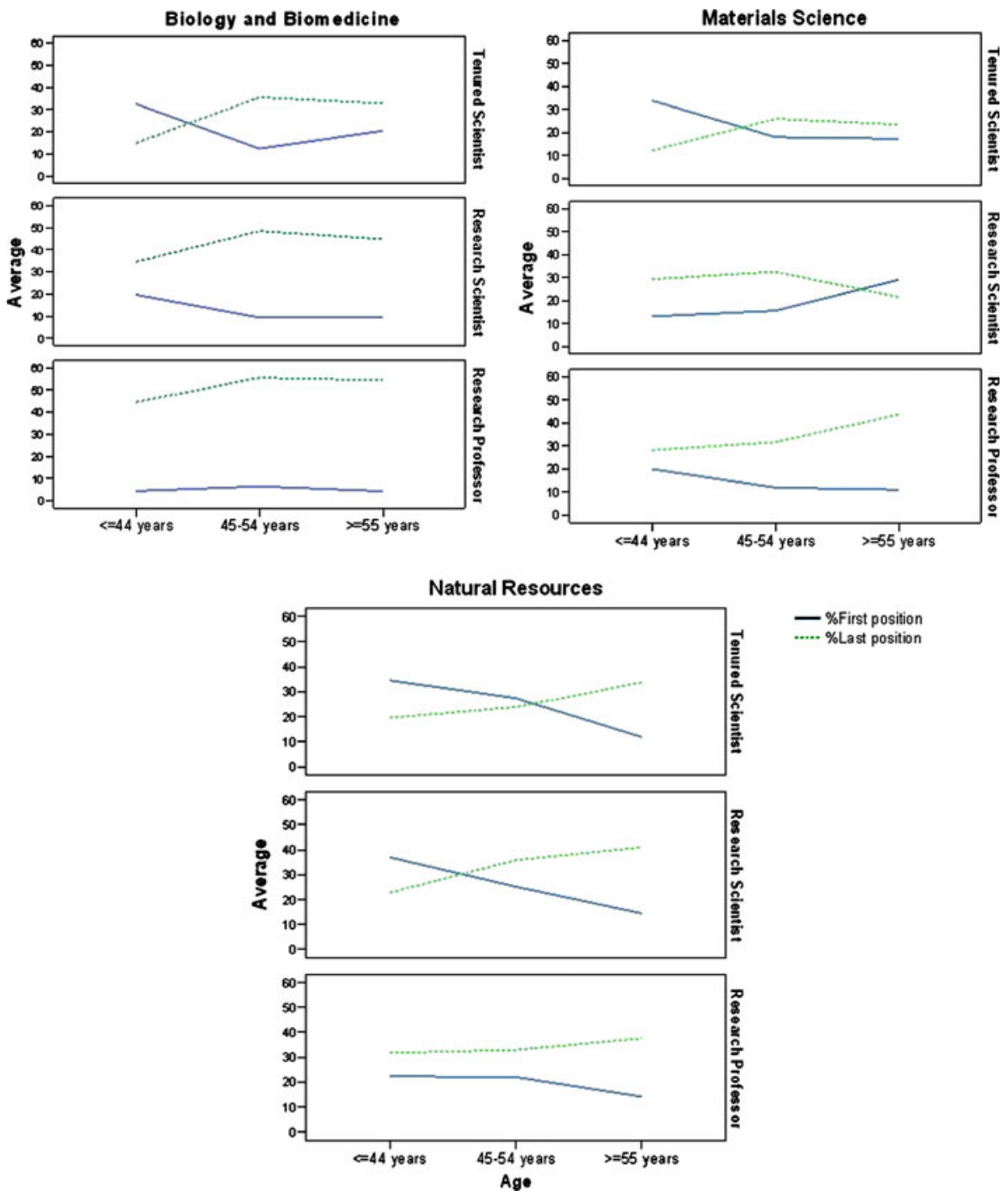

Fig. 5 Share of documents signed by scientists as first and last author by age and professional rank

These results are consistent with the previously described convention in many fields whereby the order of authors is determined by the role and extent of their contribution to the research. In many fields, first authors are those who contributed most to the experimental work and they are very often young scientists at the beginning of their professional career, while last authors are very frequently scientists of a higher professional rank and/or with longer professional trajectories who play a supervisory role. This authorship practice is in line with the results of other studies (see for example Davis and Wilson 2001; Drenth 1998) and is consistent with the perception of promotion committees in different biomedical and experimental disciplines, as shown in a study focused on a sample of medical schools (Wren and Kozak 2007).

The study of the evolution of the signing position of scientists with age is very illustrative in the three areas under analysis, since it reflects a gradual transition in the role 
played by scientists in the research process along their life cycle. Scientists at the beginning of their career tend to sign more often as first authors, as they frequently work under the supervision of a senior researcher, who usually signs in the last position. In fact, the name of the senior scientist follows that of the younger one in teacher-student collaborations in the study of Liang et al. (2004), in which $\mathrm{PhD}$ students tend to sign in first position whereas their supervisors do so in the closing one. Doctoral students are not included in our study, but tenured scientists are the most junior scientists and the youngest among them show the highest propensity to sign as first author of publications. As scientists gather experience, they may assume a supervisory role of the work of other scientists, and in many cases they will build their own group. The "shift age" at which scientists tend to adopt a more "senior" signing pattern is around 36-38.

\section{Social status and function in research}

In our study, we do not know whether the position of authors derives from the contribution of the different scientists to a given research or to social conventions such as those based in the prestige or social status of scientists within teams. It is clear that professional rank is a sign of status and we consider that age can also be associated to a certain status since older scientists usually have broader experience and knowledge. Asking authors themselves about their involvement in the research and the criteria followed for authorship would be the only way to obtain a reliable answer to this question (as developed by Hoen et al. 1998). However, our results show that social status (as measured through professional rank and age) is clearly related with author order in the byline of publications and we assume that this determines the specific functions of scientists (experimental work, supervisory tasks). In other words, structural and functional features of scientists within teams interact, they are highly dependent on one another, and taken together, contribute to the construction of the social structure within research teams.

The analysis of individual bibliometric profiles allows us to identify "top scientists", who are those with high production levels, who publish in prestigious journals and are highly rewarded with citations ("top performance"). Interestingly, our study shows that top performance is not related with any specific position in the byline of publications. The reason is that scientific class and professional rank do not perfectly match (Costas et al. 2010) as professors tend to lead research, but not necessarily with a top profile. Probably their involvement in management, supervision and coordination tasks prevents them from obtaining very selective high-quality research results. On the other hand, an increase in productivity but a slump in average impact for scientists as they get older-until in their fifties-has been described in some fields, not only for Spanish CSIC scientists (Costas et al. 2010) but also for Canadian ones (Gingras et al. 2008). As described elsewhere (Costas et al. 2010), "top scientists" at CSIC are very often young scientists, who have been recently abroad in research stays and have been involved in international collaboration. A top profile is needed at present to get tenure at CSIC after a very competitive selection process strongly based on the quantity and quality of the scientific publications of scientists. Those with a top profile are very often at the beginning of their professional career as permanent scientists at CSIC. It might be the case that they do not have a team of their own yet (Rey-Rocha et al. 2006), and therefore they contribute with their skills and knowledge to the performance of already established teams, until they consolidate their position in the institution. As a consequence, the signing patterns studied are related with age or professional rank rather than with the top or low profile of scientists. 
Age and professional rank: which is more influential on authorship order?

Our research shows (in line with previous studies) that both professional rank and age have an effect on authorship order, but differences by area have been identified. Authorship patterns are especially marked in the area of Biology and Biomedicine, where research professors show the lowest percentage of first-authored documents and the highest percentage of last-authored documents irrespective of their age. Smoother authorship patterns are observed in Natural Resources and Materials Science.

It is interesting to note that professional rank seems to be more influential than age on the authorship patterns in Biology and Biomedicine, while the effect of age seems to be equal (last authorship) or greater (first authorship) than that of rank in Natural Resources. Interestingly, a senior authorship pattern was observed for all scientists aged over 55-whatever their rank-in Natural Resources, as well as for all research professors-whatever their age-in Biology and Biomedicine. In other words, our results suggest that rank carries more weight than age in determining the role of researchers in Biology and Biomedicine, while age plays a more significant role in Natural Resources. A more difficult promotion of scientists to the upper professional rank in Natural Resources (around $45 \%$ of scientists aged over 55 are research professors in Biology and Biomedicine and Materials Science whilst only $31 \%$ have attained this rank in Natural Resources) (see Appendix) could contribute to explain this finding. In Natural Resources there are more experienced scientists outside the upper rank that seem to be research leaders according to their senior signing patterns.

Moreover, the more significant role of professional rank over age in the trend to sign as last author in publications in the field of Biology and Biomedicine could also stem from the fact that it is a highly collaborative and competitive field at the CSIC (CSIC scientists in this field publish in higher-impact factor journals and receive a higher number of citations than the national average, while Natural Resources remains below average) (Costas et al. 2010). Scientists in the upper rank are usually in a better position to obtain economic support in competitive calls for research projects and this could be the case particularly when large teams are involved.

\section{Future trends}

Our results show that studies based on the position of authors in the byline can provide useful information about the role played by scientists in research, the influence of social variables and the manner in which it evolves along the professional life of scientists. However, differences by scientific field, country and even institutional settings might exist and deserve further attention. Inter-field differences in authorship conventions should be kept in mind were conducting this type of study. Although differences by country might also exist, they are expected to be smaller due to the increasing internationalisation of science. In fact, the trend of scientists to sign more often as last author and less as first author as they get older was also described for a sample of Canadian scientists (Gingras et al. 2008). Concerning institutional settings, it is interesting to note that some authorship patterns described herein in connection with age were also reported in the abovementioned Canadian study, although our work deals with full-time researchers in a public research institution and the Gingras study focuses on university professors and university-affiliated researchers who were also involved in teaching activities. This finding suggests that the scientific community is governed by its own laws modulating the publishing strategies of different individuals on the basis of targeted specific reward structures. This supports the role of authorship as a mode of social organisation of the scientific community (Pontille 2004). 
As collaboration rises in the increasingly complex world of research, the meaning of authorship and author position in the byline is becoming more ambiguous (Pontille 2004). Multilateral collaboration in which members from more than one group are involved is increasingly frequent and may contribute to blur signing patterns. Author position in these cases can be determined after difficult negotiations among scientists, sometimes including agreements about rotation of first-authors in subsequent documents resulting from a given collaborative project or sharing 'equal first-authorship' to evenly reward members of different teams. Thus, the need to include in each publication the specific contribution of every author to the research is increasingly demanded by journals, associations and institutions (Pontille 2004; Cronenwett and Seeger 2005). The regular inclusion of this information in journals will provide important support to the decisions of evaluation committees. At the same time, these data could allow us to carry out more accurate bibliometric studies based on more detailed information, maybe through categorisation of authors' roles or through the construction of more advanced bibliometric indicators which take into account the different roles played by scientists in any given research work.

Acknowledgments This research was supported by an I3P grant by the Spanish CSIC during the initial analysis of the data. The authors are also grateful to Laura Barrios for statistical advice and to the two anonymous reviewers for their valuable comments and suggestions.

Open Access This article is distributed under the terms of the Creative Commons Attribution Noncommercial License which permits any noncommercial use, distribution, and reproduction in any medium, provided the original author(s) and source are credited.

\section{Appendix}

See Table 5

Table 5 Distribution of scientists by professional rank and age within each area

\begin{tabular}{lrrrr}
\hline & Tenured scientist & Scientific researcher & Research professor & Total \\
\hline \multicolumn{2}{l}{ Biology and biomedicine } & & & \\
\multicolumn{1}{l}{$\leq 44$ years } & $88(78.57 \%)$ & $21(18.75 \%)$ & $3(2.68 \%)$ & $112(100 \%)$ \\
$45-54$ years & $79(45.66 \%)$ & $51(29.48 \%)$ & $43(24.86 \%)$ & $173(100 \%)$ \\
$\geq 55$ years & $21(20.39 \%)$ & $33(32.04 \%)$ & $49(47.57 \%)$ & $103(100 \%)$ \\
Total & $188(48.45 \%)$ & $105(27.06 \%)$ & $95(24.48 \%)$ & $388(100 \%)$ \\
Materials science & & & & $105(100)$ \\
$\leq 44$ years & $89(84.76 \%)$ & $13(12.38 \%)$ & $3(2.86 \%)$ & $113(100)$ \\
$45-54$ years & $42(37.17 \%)$ & $3(34.51 \%)$ & $32(28.32 \%)$ & $109(100)$ \\
$\geq 55$ years & $33(30.28 \%)$ & $28(25.69 \%)$ & $48(44.04 \%)$ & $327(100)$ \\
Total & $164(50.15 \%)$ & $80(24.46 \%)$ & $83(25.38 \%)$ & $115(100)$ \\
Natural resources & & & & $132(100)$ \\
$\leq 44$ years & $96(83.48 \%)$ & $15(13.04 \%)$ & $4(3.48 \%)$ & $102(100)$ \\
$45-54$ years & $73(55.30 \%)$ & $36(27.27 \%)$ & $23(17.42 \%)$ & $349(100)$ \\
$\geq 55$ years & $37(36.27 \%)$ & $33(32.35 \%)$ & $59(16.91 \%)$ & \\
Total & $206(59.03 \%)$ & $84(24.07 \%)$ & & \\
\hline
\end{tabular}




\section{References}

AMS (American Mathematical Society). (2004 Statement). The culture of research and scholarship in Mathematics: joint research and its publication.

Bellis, N. (2009). Bibliometrics and citations analysis. Maryland: Scarecrow Press Inc.

Beveridge, C., \& Morris, S. (2007). Order of merit. Nature, 448(7152), 508.

Biagioli, M. (1998). The instability of authorship: credit and responsibility in contemporary biomedicine. FASEB Journal, 12, 3-16.

Birnholtz, J. P. (2006). What does it mean to be an author? The intersection of credit, contribution, and collaboration in Science. Journal of the American Society for Information Science and Technology, 57(13), 1758-1770.

Bordons, M., \& Gómez, I. (2000). Collaboration networks in Science. In B. Cronin \& H. B. Atkins (Eds.), The web of knowledge: a Festschrift in honour of Eugene Garfield (pp. 197-213). Medford: Information Today, Inc. \& American Society for Information Science.

Carayol, N., \& Matt, M. (2004). Does research organization influence academic production? Laboratory level evidence from a large European university. Research Policy, 33, 1081-1102.

Costas, R., \& Bordons, M. (2006). Algorithms to solve the lack of normalization in author names in bibliometric studies. Investigacion Bibliotecologica, 21(42), 13-32.

Costas, R., \& Iribarren-Maestro, I. (2007). Variations in content and format of ISI databases in their different versions: the case of the Science Citation Index in CD-ROM and the Web of Science. Scientometrics, 72(2), 167-183.

Costas, R., van Leeuwen, T. N., \& Bordons, M. (2010). A bibliometric classificatory approach for the study and assessment of research performance at the individual level: the effects of age on productivity and impact. Journal of the American Society for Information Science and Technology, 61(8), 1564-1581.

Cronenwett, J. L., \& Seeger, J. M. (2005). Criteria for authorship. Journal of Vascular Surgery, 42, 599.

Cronin, B., \& Shaw, D. (2002). Identity-creators and image-makers: using citation analysis and thick description to put authors in their place. Scientometrics, 54(1), 31-49.

Davis, M., \& Wilson, C. S. (2001). Elite researchers in ophthalmology: aspects of publishing strategies, collaboration and multi-disciplinarity. Scientometrics, 52(3), 395-410.

Drenth, J. P. H. (1998). Multiple authorship. The contribution of senior authors. JAMA, 280(3), $219-221$.

Engers, M., Gans, J. M., Grant, S., \& King, S. P. (1999). First-author conditions. Journal of Political Economy, 107(4), 859-883.

Feist, G. J. (1993). A structural model of scientific eminence. American Psychological Society, 4(6), $366-371$.

Fox, M. F. (2005). Gender, family characteristics, and publication productivity among scientists. Social Studies of Science, 35(1), 131-150.

Fox, M. F., \& Stephan, P. E. (2001). Careers of young scientists: preferences, prospects and realities by gender and field. Social Studies of Science, 31(1), 109-122.

Frandsen, T. V., \& Nicolaisen, J. (2010). What is in a name? Credit assignment practices in different disciplines. Journal of Informetrics, 4(4), 608-617.

Gingras, Y., Lariviere, V., Macaluso, B., \& Robitaille, J. P. (2008). The effects of aging on researchers' publication and citation patterns. PloS ONE, 3(12), e4048.

Hara, N., Solomon, P., Kim, S.-L., \& Sonnenwald, D. H. (2003). An emerging view of scientific collaboration: scientists' perspectives on collaboration and factors that impact collaboration. Journal of the American Society for Information Science and Technology, 54(10), 952-965.

Hemlin, S., \& Gustafsson, M. (1996). Research production in the arts and humanities: a questionnaire study of factors influencing research performance. Scientometrics, 37(3), 417-432.

Hoen, W. P., Walvoort, H. C., \& Overbeke, A. J. P. M. (1998). What are the factors determining authorship and the order of the author's names? Journal of the American Medical Association, 280(3), 217-218.

Hu, X. (2009). Loads of special authorship functions: linear growth in the percentage of "Equal First Authors" and "Corresponding Authors". Journal of the American Society for Information Science and Technology, 60(11), 2378-2381.

Hu, X., Rousseau, R., \& Chen, J. (2010). In those fields where multiple authorship is the rule, the h-index should be supplemented by role-based h-indices. Journal of Information Science, 36(1), 73-85.

ICMJE (International Committee of Medical Journal Editors) (2010). Uniform requirements for mauscripts submitted to biomedical journals. www.icmje.org.

Kalyane, V. L., \& Munnolli, S. S. (1995). Scientometric portrait of T.S. West. Scientometrics, 33(2), 233-256.

Liang, L., Liu, J., \& Rousseau, R. (2004). Name order patterns of graduate candidates and supervisors in Chinese publications: a case study of the three major Chinese universities. Scientometrics, 61(1), 3-18. 
Mattsson, P., Sundberg, C. J., \& Laget, P. (2010). Is correspondence reflected in the author position? A bibliometric study of the relation between corresponding author and byline position. Scientometrics, 87, 99-105.

Mauleon, E., \& Bordons, M. (2006). Productivity, impact and publication habits by gender in the area of Materials Science. Scientometrics, 66(1), 199-218.

Mauleon, E., \& Bordons, M. (2007). Women involvement in editorial board of Mathematics journals. 11th International Conference of the International Society for Scientometrics and Informetrics (pp. 552-557). Madrid: CINDOC-CSIC.

Mendki, P. S. (2006). Authorship criteria for maintaining healthy culture of research publications. Current science, 90(11), 1457.

Moed, H. F. (2000). Bibliometric indicators reflect publication and management strategies. Scientometrics, 47(2), 323-346.

Osborne, J. W., \& Holland, A. (2009). What is authorship, and what should it be? A survey of prominent guidelines for determining authorship in scientific publications. Practical assessment, research and evaluation, 14(15), 1-19.

Pontille, D. (2004). La signature scientifique. Paris: Editions du CNRS.

Prakasan, E. R., Kalyane, V. L., \& Kumar, V. (2009). Sustained impact of publications of CV Raman. Scientometrics, 78(1), 77-97.

Prpic, K. (2000). The publication productivity of young scientists: an empirical study. Scientometrics, 49(3), 453-490.

Rey-Rocha, J., Garzón-García, B., \& Martín-Sempere, M. J. (2006). Scientists’ performance and consolidation of research teams in Biology and Biomedicine at the Spanish Council for Scientific Research. Scientometrics, 69(2), 183-212.

Savitz, D. (1999). What can we infer from author order in epidemiology? American Journal of Epidemiology, 149(5), 401-403.

Shapiro, D. W., Wenger, N., \& Shapiro, M. F. (1994). The contributions of authors to multiauthored biomedical research papers. Journal of American Medical Association, 271(6), 438-442.

Tscharntke, T., Hochberg, M. E., Rand, T. A., Resh, V. H., \& Krauss, J. (2007). Author sequence and credit for contributions in multiauthored publications. PLOS Biology, 5(1), e18.

Vinkler, P. (2010). The evaluation of research by scientometric indicators. Oxford: Chandos Publishing.

Wren, J. D., \& Kozak, K. Z. (2007). The write position. A survey of perceived contributions to papers based on byline positions and number of authors. EMBO reports, 8(11), 988-991.

Zuckerman, H. A. (1968). Patterns of name ordering among authors of scientific papers: a study of social symbolism and its ambiguity. The American Journal of Sociology, 74(3), 276-291. 